\title{
Vegetation Types in Surrounding Landscape of Alpine Lake Saif-ul-Mulook, Western Himalaya, Pakistan
}

\author{
Zia-ur-Rehman Mashwani, Mir Ajab Khan, Mushtaq Ahmad, Muhammad Arshad, and Audil Rashid
}

\begin{abstract}
Lake Saif-ul Malook is located in Naran valley of Western Himalay, North Pakistan. The distribution of plant communities and the pattern of species diversity were studied along alpine lake Saif-ul-Mulook. Field analysis of vegetation was carried out by selecting the six sites in order to cover all the geographical variation. Vegetation survey was done by collection data by using five line intercept transects $(20 \mathrm{~m}$ each) from each site. Results of Two Way Indicator Species Analysis (TWINSPAN) classification have identified three groups of plant communities that were exploited at different levels along the lake. Detrended Correspondence Analysis (DCA) clearly distinguished these groups by the first two DCA axes. Both classification and ordination resulted in a clear demonstration of the vegetation pattern in the study area. Variation in the diversity and the distributional pattern of plant species and communities in the study area may be attributed chiefly to anthropogenic and grazing pressures. The implications of the results are discussed and recommendations are suggested for conservation and sustainable utilization of vegetation.
\end{abstract}

Index Terms-Alpine vegetation, Lake Saif-ul-Mulook, Twinspan, DCA, Western himalaya.

\section{INTRODUCTION}

Phytosociological surveys are important tools of ecologists to assess and evaluate the vegetation types of given ecosystem. These ultimately help in planning, management and exploitation of natural resources since important components of food chain viz., human, livestock, wildlife and soil fauna are closely associated with specific plant assemblages of the area.

Floral assessment is an important criterion for the assessment of life forms and habitat of an area. Phytosociology is the science that describes the diversity in plant communities. It is the study of the characteristics, classification, relationships, and distribution of plant communities [1].

Phytosociology attempts to describe the diversity in plant communities and its methods often involve the quantative estimation of various parameters of vegetation like cover, abundance and frequency etc. TWINSPAN [2], is one of the classification utilities that are most widely used by phytosociologists for floral biodiversity assessment. It is a FORTRAN based program for Two- Way Indicator Species

Manuscript received September 16, 2011; revised November 1, 2011.

Zia-ur-Rehman Mashwani and Muhammad Arshad are with the Department of Botany, PMAS arid Agriculture University, Rawalpindi, Pakistan (e-mail: zia.botany@gmail.com, phone: +92-333-9022077).

Mir Ajab Khan and Mushtaq Ahmad are with the Department of Plant Sciences, Quaid-i-Azam University, Islamabad, Pakistan.

Audil Rashid is with the Department of Environmental Sciences, PMAS Arid Agricultural University, Rawalpindi, Pakistan.
Analysis and is an improvement upon the original Indicator Analysis. The results obtained by TWINSPAN are similar to that of Braun-Blanquet's table arrangements. This analysis resulted in the identification of four sub- communities of trees. Difference in species composition between the communities and sub-communities was found related to difference in topography of the area.

Saif-ul-Mulook, a high altitude alpine lake located at the northern end of the Kaghan Valley (34 $52^{\prime} 37.34^{\prime \prime} \mathrm{N}$ $\left.73^{\circ} 41^{\prime} 37.71^{\prime \prime} \mathrm{E}\right)$ near Naran. It is in the north east of Mansehra District in the Khyber-Pukhtoonkhwa Province, Pakistan. Its elevation varies from 3300 to $5490 \mathrm{~m}$ above sea level amongst one of the highest lakes in Pakistan.

Most of the area has steep slopes and exposed peaks. Some of the peaks remain covered with glaciers and provide melt-water throughout the year. This uncontrolled heavy seasonal grazing is one of the major causes of degradation and retrogression of this pasture. The pasture deterioration is proceeding unchecked as no technical inputs are being provided by any agency. There is need to reverse the degradation processes and to improve the pasture according to its potential productivity.

\section{MATERIAL AND METHODS}

\section{A. Field Survey}

The study was carried out during September 2010. This was the best time for vegetation study because most of the plants were in bloom at this time. The information about the plants was gathered following [3]-[5].

\section{B. Sampling Design}

A total of 06 sites were selected and 4-5 line intercept transects per site was recorded. Each transects line representing respective sampling point distributed randomly over the entire periphery of the lake.

The choice of a sampling design depends upon the aims and objectives of the study, available time and resources, type of habitat and proposed methods of data analysis and presentation [6]. Before deciding as to which sampling design was appropriate for this study, the points that were considered include: size of the study area, time available for field work, nature of terrain, weather, and the availability of a topographic map and geo-referenced satellite image.

Stratified random sampling designs could not be applied in this study due to the lack of a large-scale topographic map or a geo-referenced satellite image of the area during fieldwork. Without a large scale georeferenced image or topographic map, it is not possible to mark random points, which could then be identified correctly on the ground. 


\section{1)Locations of sampling sites in study area}

Keeping in view the above constraints random sampling design was chosen in such a way that maximum geographic extent could be covered.

TABLE I: SHOWING THE LOCATION OF THE SAMPLING SITES

\begin{tabular}{|c|c|c|}
\hline Transect No. & Longitude & Latitude \\
\hline 1 & 345251.1 & 734145.8 \\
\hline 2 & 345242.4 & 734149.8 \\
\hline 3 & 345233.3 & 734155.1 \\
\hline 4 & 345224.2 & 734127.5 \\
\hline 5 & 345234.9 & 734123.7 \\
\hline 6 & 345252.7 & 734130.4 \\
\hline
\end{tabular}

For detailed data collection line transect survey was selected which is a very popular vegetation survey technique (Kent and Coker, 1992).

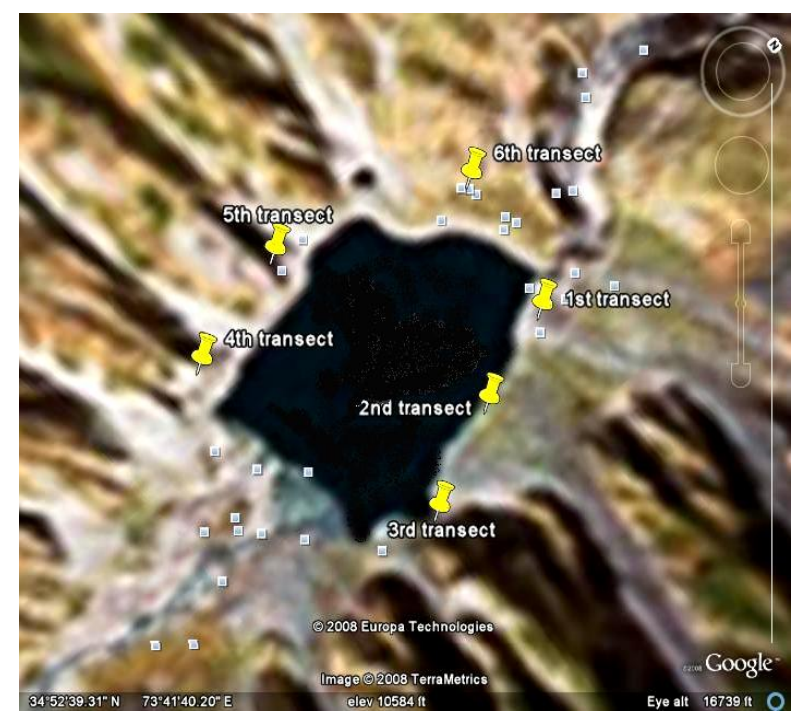

Fig. 1. Distribution of the six sites along the Lake Saiful Malook (Google Maps).

Prior to the commencement of fieldwork a short reconnaissance survey was undertaken to get an overview of the area. The transects were laid out in locations selected in the field as being representative of the environmental variability so as to cover variation in site conditions

\section{2)Field data collection}

Field data were collected from within sample plots. Location and biological data was recorded from the sampling plots. Location data was the GPS readings that were taken while standing in the middle of transect line, laid parallel to the periphery of lake in order to avoid the edge effect. The biological data was collected to be able to make a statement on floral diversity and species composition. It included species dominance and abundance data (=cover abundance), recorded in the transect line using the line intercept method (Canfield 1940).

Besides the plants occurring along transects, an effort was made to collect the plants from all accessible parts along the sampling localities, settlements and roadsides to develop a baseline on floral biodiversity in the study area.

\section{Statistical Analysis}

The sample size required in any study is determined by the objective of the study, the resources available, type of study, variability of the characteristic to be measured, the precision required and the required confidence that the precision is valid (Kaewsonthi and Harding, 1992). Time was a major limiting factor in this study. Thus it was not possible to cover the whole area for detailed sampling.

\section{1) TWINSPAN classification analysis}

The cover abundance data of sampling locations was instated to TWINSPAN [7] with the aim to record the floristic variation and to detect natural groups of sampled plots.

Oksanen and Minchin (1997) pointed out the extremely lax criteria for stability of the RA solutions at the root of TWINSPAN. This caused instability in the results depending on sample order. The method used here apply Oksanen and Minchin's (1997) "super strict" criteria of tolerance $=0.0000001$ and maximum number of iterations $=$ 999, replacing the old criteria of tolerance $=0.003$ and maximum iterations $=5$. The analysis was performed with a modified version of program TWINSPAN from the Cornell Ecology Program Series (Hill, 1979a).

TWINSPAN [7], [8] simultaneously classifies species and samples. At its core, TWINSPAN is based on dividing a reciprocal averaging ordination space [9].

\section{2)Detrended correlation analysis (DCA, DECORANA)}

Species abundance data was also analyzed through DCA (detrended correspondence analysis). Detrended corresponddence analysis (DCA) has been quite popular in ecology. It is geared to ecological data sets based on samples and species [10]. It is an eigen-analysis ordination technique based on reciprocal averaging [11].

The analysis was performed with a modified version of DECORANA from the Cornell Ecology Program series [2]. Earlier versions of DECORANA were unstable because of lax criteria for stability and a bug in the rescaling algorithm [12]. We now apply Oksanen and Minchin's "super strict" criteria.

TABLE II: SHOWING THE RESULTS OF THE TWINSPAN

\begin{tabular}{l|c|c|c|c|c|l}
\hline & 1 & 3 & 2 & 6 & 5 & 4 \\
\hline Dryopteris stewersii & - & - & 1 & - & 1 & - \\
Sibbaldia cunnata & - & 1 & - & - & 1 & - \\
Anaphalis triptriplinervous & - & - & - & - & 1 & - \\
Salix flabilaris & - & - & - & - & 1 & - \\
Ranunculus laetus & - & 1 & 1 & - & 1 & - \\
Poa alpine & 1 & 1 & 1 & 1 & 1 & - \\
Astragulus & 1 & 1 & 1 & 1 & - & - \\
Phleum alpinum & 1 & 1 & 1 & 1 & - & - \\
Taraxicum officinales & 1 & 1 & 1 & 1 & - & - \\
Trifollium repens & 1 & 1 & 1 & - & - & - \\
Sambucus wightiana & - & - & - & 1 & - & - \\
Verbascum Thapsus & - & - & - & 1 & - & - \\
Fragaria nubicola & - & - & 1 & 1 & - & - \\
Irus germanica & - & - & 1 & 1 & - & - \\
Rumex nepalensis & - & 1 & - & 1 & - & - \\
Oxyria digyna & - & 1 & 1 & - & - & - \\
Senihem & - & 1 & 1 & - & - & - \\
Impation edgwartii & - & 1 & - & - & - & - \\
Capsella barsa pestoris & - & - & 1 & - & - & - \\
Plantago ovata & - & - & 1 & - & - & - \\
Thymus liniaris & 1 & 1 & 1 & - & - & 1 \\
Cotoneaster microphyllus & - & - & - & 1 & 1 & 1 \\
Berginia strchyii & - & - & - & - & 1 & 1 \\
Artemisia absenthium & - & - & - & - & - & 1 \\
Juniper communis & - & - & - & - & - & 1 \\
Rheum emodi & - & - & - & - & - & 1 \\
& 0 & 0 & 0 & 0 & 0 & \\
\hline & & & & & Level1 \\
\hline & & & &
\end{tabular}




\section{RESULTS}

The study area lies essentially in the alpine zone. According to traditional definitions, like that of Troll method [13], the alpine belt can be defined as the principally treeless area above the upper limit of Betula (Birchwood forests).

\section{A. TWINSPAN Analysis}

The plant communities that were perceived through the analysis of data include:

\section{1) Poa-Taraxicum-Phleum-Astragalus Community}

The indicator species for this plant community were Poa alpina, Phleum alpinum Astragalus leucocephalus and Taraxicum officinales. In some places Trifollium repens and Thymus liniaris were also present in significant numbers. Such association was observed in the areas where there was less local moisture available. And positions all these sites were along the landscape area of the lake.

\section{2) Berginia-Cotoneaster-Anaphalis-Salix Community}

This plant community was dominated by occurrence of Berginia strchyii, Cotoneaster microphyllus, Anaphalis triptriplinervous and Salix flabilaris, and form a very different community in the area. The area was characterized by the greater degree of slopes and soil has more proportion of humus. This site represents the inlet area of the lake, with different pattern of vegetation structure.

\section{3) Juniper-Artemisia-Rheum Community}

This plant community occurred at the locations where there was ample accumulation of moisture like crevices etc. The indicator species for this plant community were Juniper communis and Artemisia absenthium. The site was selected at the outlet area of the lake with different topography and different soil structure, resulted in distinct pattern of vegetation.

\section{B. Detrended Correspondence Analysis}

The analysis show similar results as inferred by TWINSPAN analysis. There is an understandable distribution of vegetation along DCA axis 1 is along moisture gradient. It can be looked upon as major factor controlling the distribution of vegetation in study area. From right to left along DCA axis 1 there is a shift from vegetation of drier parts to those of wetter localities. Along DCA axis 2 not much of segregation of vegetation groups can be observed.

The analysis was performed with a modified version of DECORANA from the Cornell Ecology Program series (Hill 1979). Earlier versions of DECORANA were unstable because of lax criteria for stability and a bug in the rescaling algorithm (Oksanen and Minchin 1997). We now apply Oksanen and Minchin's "super strict" criteria.

\section{Status of the Species}

A total of 26 species belonging to 17 families of vascular plants are being reported from Saif-ul-Mulook Lake and its adjoining areas that were observed during the fieldwork. Family-wise proportion of the species is shown in Fig. 3.

Asteraceae is the family that is most representative in (15.38\%), and together with Ranunculaceae, Compositae, Ranunculaceae, Cruciferae, Gramineae, Apiaceae, Leguminosae, Scrophulariaceae and Polygonaceae are the families that constitute the bulk of local flora.

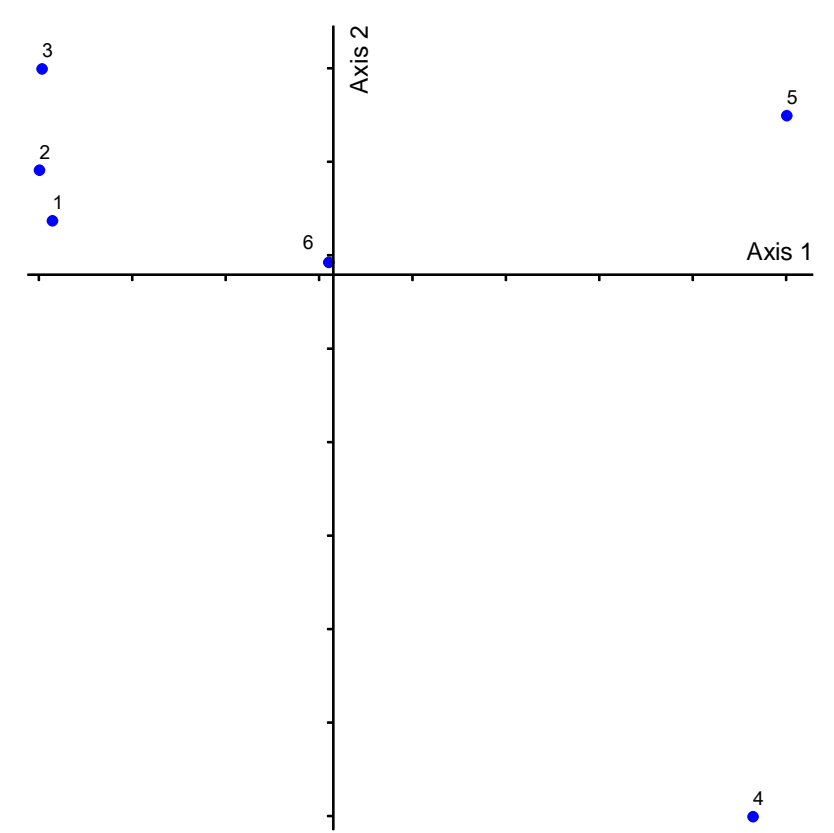

Fig. 2. Ordination diagram and spatial distribution of communities at Saif-ul-MulookLake area. (1. 2. 3. 6. Poa-Taraxicum-Phleum-Astragalus Community; 5. Berginia- Cotoneaster- Anaphalis- Salix Community; 4. Juniper-Artemisia-Rheum Community)

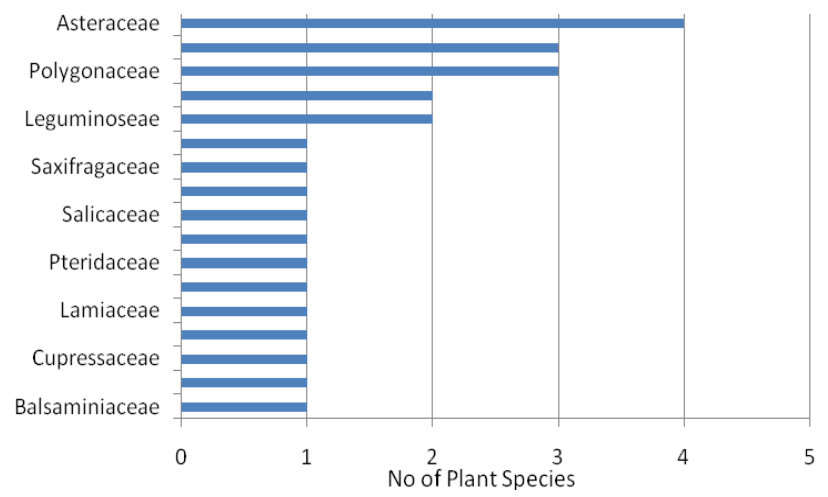

Fig. 3. Family-wise proportion of flora of Lake Saif-ul-Mulook and Surroundings.

The chorological spectrum of the flora of Saif-ul-Mulook Lake and adjoining areas (Fig.3) shows that the cosmopolitan species are in lowest proportion and the highest proportion belong to Eurasiatic elements. Those endemic to Hindukush Himalayan $(\mathrm{HKH})$ region are $15 \%$ of the total flora. Centrasiatic, and Sino-Himalayan elements show medium proportion. Other flora has affinities with Irano-turanian, medeterranian, Tibetan and Circumpolar phyto-geographical regions. These facts show that the flora of the study area is unique due to high endemism in flora. Most of the flora has distribution restricted to Northern Pakistan or adjoining areas.

It must be stated that complete information on flora of the study area is still lacking and the area needs to be thoroughly explored in this regard.

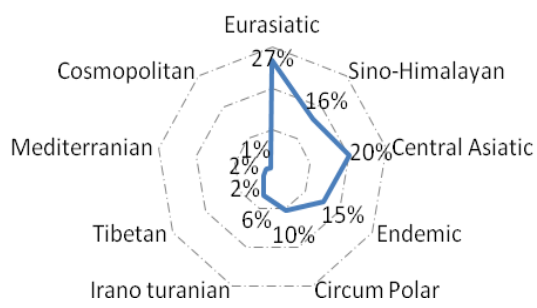

Fig. 4. Chorological spectrum of Saif-ul-Mulook Lake and its surroundings. 


\section{ETHNOBOTANICAL RESEARCH}

The existing ethnobotanical knowledge needs further research and improvements. Comprehensive inventories of plant resources and assessments of their uses are lacking; such inventories are sorely needed. Research should emphasize case studies, especially those that identify and analyze the causes of success and failure in plant product development.This may include:

1. Surveys and analyses of the degree and extent of the subsistence and local uses of plant resources should be conducted prior to encouraging more intensive commercial exploitation.

2. Marketing analyses that follow specific non-wood forest products from collection to final consumer are needed for a variety of products.

3. Better linkages should be developed among the numerous networks and organizations already dealing with forest products.

4. Producers, buyers, and consumers should be sensitized and made aware of the value of FPs and the issues related to their development and exploitation.

5. Cultivation of medicinal plants should be introduced.

Other specific research should be conducted on:

6. The supply and demand of NTFPs, currently and in the future

7. Indigenous systems of local knowledge and resource management

8. The connection between tenurial security and the sustainable development of NTFPs

9. The role of gender in resource management

10. Appropriate technologies for NTFPs harvest, use, and processing

11. Training should be expanded to provide greater emphasis to non-wood forest resources and their productions, utilization, and marketing.

12. Where local knowledge and experience inadequate, practical training should be provided to local growers, collectors, and processors of forest products to ensure sustainable and efficient use of the resources and to increase local income levels.

\section{DISCUSSION}

The study area lies essentially in the alpine zone. According to traditional definitions, like that of Troll (1939), the alpine belt can be defined as the principally treeless area above the upper limit of Betula (Birchwood forests).

The alpine vegetation of the study area consists of an often small-scale mosaic of (dwarf) scrub, meadow, turf, open scree and rock vegetation types (Burzil pass). The distribution of alpine plant communities is influenced by relief, exposure and edaphical features. Scrub and dwarf scrub ("Krummholz") of Salix karelinii, attaining a height from 20 to $200 \mathrm{~cm}$ depending on conditions, cover large tracts on $\mathrm{N}$ facing slopes above the subalpine Betula forests and along valleys and avalanche trails.

Humid conditions allow the accumulation of deep layers of forest humus, providing habitat for a variety of tall hygrophilous forbs (Aconogonon alpinum, Gentiana sp,
Geranium sp.), some of which are perhaps more characteristic to the subalpine belt, as well as a companion flora of smaller herbs (Gentiana marginata, Vicatia wolffiana, Sibbaldia cuneata, Pedicularis pectinata).

Sometime dwarf shrubberies (30-60 cm in height), provide enough shelter for alpine herbs and dwarf shrubs (Trollius acaulis, Thalictrum, Carex sp. etc). Relatively large areas are covered by alpine turf or mats, with various sedges along with companion species like Saussurea falconeri, Potentilla sp, Androsace, Rhodiola sp., Anaphalis sp., Saxifraga flagellaris, Myosotis sp., Erigeron multiradiatus, Draba lanceolata, Androsace septentrionalis, Oxytropis sp, Ranunculus, Leontopodium leontopodinum, Chorispora sabulosa). In accordance with exposure, humidity conditions and grazing intensity, many of these and other species may form aspects of their own. A special association of "snow valleys" (Salix flabellaris, Primula reptans), reminiscent of a typical feature of humid alpine mountains, is confined to permanently moist situations with long lasting snow-cover along avalanche trails.

Edaphically dry or intensively grazed slopes are usually covered with more open "meadow-steppes", where chamaephytes (Bistorta affinis, Rhodiola etc.) and drought-resistant herbs (Elymus, Oxytropis, Silene) dominate. Juniper patches (Juniperus communis subsp. alpina) may also extend into the alpine belt on southern aspects.

Sometime dwarf shrubberies ( $30 \mathrm{~cm}$ to $60 \mathrm{~cm}$ in height), provide enough shelter for alpine herbs and dwarf shrubs. In accordance with exposure, humidity conditions and grazing intensity, many of these and other species may form aspects of their own. A special association of "snow valleys" (Salix flabellaris), reminiscent of a typical feature of humid alpine mountains, is confined to permanently moist situations with long lasting snow-cover along avalanche trails.

\section{RECOMMENDATIONS}

As a general remark it can be stated that our current knowledge of flora of Kaghan valley is still lacking. There is a need for comprehensive studies regarding different aspets of Saiful Malook flora because of the presence of precious medicinal plants. The medicinal floral guide book of Saiful Malook along with photographs should be published. Proper timing for floral survey is a must to attain good information.

\section{A. Development of a Standerdized Database on Flora of Kaghan Valley}

It is suggested that information on Kaghan valley flora be added to a standered database such as TURBOVEG or Biograd (BIOlogical Geo-referenced RelAtional Database) that will be helpful in monitoring the vegetation.

\section{B. Computerized Data Bank of Standardized Vegetation Data}

A databank consisting of standardized vegetation data will be helpful in providing information such as:

- Floristic composition

- Geographical distribution of plant communities etc.

- Planning and management of ecological resources

- Modeling the vegetation change under different circumstances 


\section{Potential Vegetation Map}

If locality of the relevés is entered by means of the geographical co-ordinates a distribution map can be drawn i.e., Potential Vegetation Map of the area. That will be much more enlightening than the satellite image map. It is suggested that the both approaches be used side by side to improve the present state of knowledge (see also Anon. 2000).

\section{New Data Collection and Rectification of the Existing Data}

The areas surveyed during present study and other areas should be visited again keeping in view proper season for proper phytosociological and vegetation data collection.

\section{E. Rotational Grazing}

Although rotational grazing is often referred to as a very good intervention to improve rangeland conditions, and the local people are well aware of this phenomenon and are practicing it. The other interventions can be made.

\section{F. Reduction in Number of Livestock}

That is, those animals that are not productive could be curtailed e.g., male livestock.

\section{G. Fenced Vegetation Patches in Pastures}

If small patches of land cover be fenced at regular intervals in pastures, a reasonable population of plants could be expected to complete their life cycles and producing viable seeds. These viable seeds will be helpful in improving the rangeland conditions by introducing new growth.

\section{H. Time Delay Strategy}

The locals can both start journey towards their pastures a bit late in spring and leave the pastures somewhat early in fall to reduce the pressure on pastures. This will give pastures a chance to recover

\section{REFERENCES}

[1] The American Heritage Dictionary, 4th ed. (21st Century Reference), Houghton Mifflin Company.

[2] M. O. Hill, DECORANA - a FORTRAN program for detrended correspondence analysis and reciprocal averaging. Ithaca, NY.: Ecology and Systematics, Cornell University, 1979.

[3] D. T. Blumstein, A Tourist Guide to Khunjerab National Park. WWF-Pakistan, 1996

[4] P. Kachroo, B. Sapru, and U. Dhar, 1977. Flora of Ladakh: An Ecological and Taxanomical Appraisal. New Delhi: Bisen Singh and Mahendra Pal Singh.

[5] Kitamura Shiro, Plants of West Pakistan and Afghanistan. Karachi: Indus Publications, 1964.

[6] M. Kent and P. Coker, Vegetation Description and Analysis: A Practical Approach. John Wiley \& Sons: New York, 1992.

[7] M. O. Hill, 1979a. TWINSPAN--A FORTRAN program for arranging multivariate data in an ordered two-way table by classification of the individuals and attributes. Ithaca, NY: Ecology and Systematics, Cornell University.

[8] H. G. Gauch, Jr. and R. H. Whittaker, 1981. Hierarchical classification of community data, Journal of Ecology 69: 135-152.

[9] H. G. Gauch, Jr. 1982. Multivariate Analysis in Community Ecology. New York: Cambridge University Press.

[10] M. O. Hill and H. G. Gauch. 1980. Detrended correspondence analysis: an improved ordination technique. Vegetatio 42: 47-58.

[11] M. O. Hill, (1973). Reciprocal averaging: An eigenvector method of ordination. Journal of Ecology, 61, 237-249.

[12] J. Oksanen and Minchin, P. R. (1997) Instability of ordination results under changes in input data order: explanations and remedies. Journal of Vegetation Science, 8, 447-454.

[13] C. Troll (1939) Das Pflanzenkleid des Nanga Parbat. Begleitworte zur Vegetationskarte 1: 50,000. Wiss Veroff. Mus. Landes-kunde, Leipzig. N. F. 7: 149-194. 